\title{
THE HAEMODYNAMIC EFFECTS OF NITRIC OXIDE
}




\section{This page is intentionally left blank}




\section{THE HAEMODYNAMIC EFFECTS OF}

NITRIC OXIDE

\section{Editors}

\section{Robert T. Mathie}

Division of Surgery, Anaesthetics \& Intensive Care, Imperial College School of Medicine, Hammersmith Hospital, London, UK

\section{Tudor M. Griffith}

Department of Diagnostic Radiology,

University of Wales College of Medicine, Cardiff, UK 


\section{Published by}

Imperial College Press

57 Shelton Street

Covent Garden

London WC2H 9HE

\section{Distributed by}

World Scientific Publishing Co. Pte. Ltd.

P O Box 128, Farrer Road, Singapore 912805

USA office: Suite 1B, 1060 Main Street, River Edge, NJ 07661

UK office: 57 Shelton Street, Covent Garden, London WC2H 9HE

\section{British Library Cataloguing-in-Publication Data}

A catalogue record for this book is available from the British Library.

\section{THE HAEMODYNAMIC EFFECTS OF NITRIC OXIDE}

Copyright $\odot 1999$ by Imperial College Press

All rights reserved. This book, or parts thereof, may not be reproduced in any form or by any means, electronic or mechanical, including photocopying, recording or any information storage and retrieval system now known or to be invented, without written permission from the Publisher.

For photocopying of material in this volume, please pay a copying fee through the Copyright Clearance Center, Inc., 222 Rosewood Drive, Danvers, MA 01923, USA. In this case permission to photocopy is not required from the publisher.

ISBN $\quad 1-86094-081-1$

Printed in Singapore. 
To Hannah and Kirstie, Kate, Richard and Robert 


\section{This page is intentionally left blank}




\section{Foreword}

Nitric oxide (NO) is a ubiquitous signalling molecule with fundamental roles now apparent not only in vertebrates and invertebrates but also in insects and plants. Thus, NO is likely to have been one of the earliest regulatory molecules to appear during biological evolution. In the cardiovascular system, the haemodynamic forces of pulsation and shear regulate $\mathrm{NO}$ synthesis by the endothelial monolayer that lines the vascular tree on a moment-to-moment basis, thus dynamically regulating perfusion at a local level. This simple but elegant method of control is likely to have antedated the role of the autonomic nervous system in the regulation of the circulation.

In the mid-1970s, NO was shown to be a potent vasodilator and inhibitor of platelet aggregation by activating the enzyme guanylate cyclase, and to mediate the pharmacological actions of nitroglycerine, the principal drug used in the treatment of angina for over 100 years. Furchgott's recognition of the pivotal role of the endothelium in mediating vascular relaxations to acetylcholine then led to a new era in vascular biology. This culminated in the identification of Furchgott's endothelium-derived relaxing factor (EDRF) as NO. Since then, an explosion of research has shown that $\mathrm{NO}$ contributes to signalling in virtually all mammalian cell types. Indeed, a simple Internet search reveals that there are some 30,000 publications in the field, over 7,000 of which deal with the cardiovascular system. Under normal physiological conditions NO helps to maintain cardiovascular efficiency in its broadest sense.

This volume is the first to address in depth the specific role of NO in cardiovascular haemodynamics. The editors have assembled authoritative contributions from leading groups in a number of areas ranging from the role of NO in the heart itself to its role in the peripheral microcirculation. The initial chapters of the book summarize current knowledge about the synthesis, chemistry and metabolic fate of NO, the cellular mechanisms that underlie its mode of action in vascular smooth muscle and the effects of mechanical forces on the endothelial cell which underpin its haemodynamic role. Molecular biological and physiological approaches have both provided important information about the control of the circulation by NO. This volume exemplifies how valuable such complementary insights may be. Later chapters examine the role of NO in the regulation of perfusion in specific organ systems, focusing on the brain, heart, skeletal muscle, liver, intestine, kidney, and lung. These chapters highlight similarities, differences and organ-specific features which may be of particular 
physiological importance. Several chapters discuss the interaction of NO with other important vascular control systems including the prostaglandin pathway and mediators such as the endothelium-derived hyperpolarizing factor.

As well as beneficial effects, $\mathrm{NO}$ also has a "dark side" in that an inducible isoform of NO synthase can produce large amounts of NO in a variety of pathological situations. These include septic shock, where excessive NO production may result in profound vasodilatation and circulatory collapse. While the chemical structure of NO may be deceptively simple, its biological chemistry is extremely complex, particularly in pathophysiological states where reactions with other free radicals such as the superoxide anion generate toxic compounds that cause cell damage. In the cardiovascular system such free radical interactions may contribute to the genesis of atheroma, ischaemia-perfusion injury and neuronal death following cerebral ischaemia. All these important aspects are covered here, together with a discussion of possible therapeutic strategies and their likely limitations.

The comprehensive coverage of the role of NO in the cardiovascular system provided in this volume serves as a springboard for those wishing to assess the role of NO in the regulation of blood flow. As many basic principles have now been established, it also serves as an important source of reference even though new twists to the tale are continuously being revealed as research progresses. In addition, this volume will be an important resource to workers in a wide range of medical disciplines, for blood flow is central to the maintenance of tissue viability in all organs. The editors are to be congratulated on assembling such an important volume, with contributions from many of the leaders in the field.

Sir John Vane The William Harvey Research Institute, London 


\section{Preface}

Since the identification of endothelium-derived relaxing factor as NO in 1987, the elucidation of its many biological effects and mechanisms of action has developed at an extraordinary rate. NO is now implicated in many physiological and pathological processes, including not just the control of vascular resistance, but also autonomic nerve transmission, cell proliferation and the response to inflammation. Many scientific symposia and review articles during the last decade have helped the international research community to keep abreast of developments in the ever diversifying branches of NO investigation, and a journal dedicated to NO research in general has recently been launched.

Given the crucial importance of NO in the cardiovascular system, it seemed to us particularly relevant to introduce a text encompassing this particular aspect of NO. Nearly twenty years after the discovery of the pivotal role of the endothelium in blood flow regulation, we therefore consider it opportune to concentrate on the field of NO and haemodynamics, and provide a comprehensive framework of information from within this active field of research. The need for such a book is clear. It is very difficult for those new or peripheral to the field to extract the relevant details from the vast literature. Even for those actually involved in cardiovascular NO research, it is almost impossible to maintain a close grasp of associated specialised topics.

We believe that the presentation and critical evaluation of existing knowledge by internationally recognised specialists has created an important reference work. In an area of research moving at such a rapid pace, we naturally recognise that fresh discoveries can swiftly supersede what seemed to be established facts. However, we and our contributing authors have done our utmost to ensure that the literature cited throughout the text reflects current awareness of the subject. Thus, we hope the book will be of lasting benefit to those new to the topic as much as to those actively engaged in NO research, including physicians who have begun to apply basic discoveries to the management of the many disease processes now known to be linked in some way to the action of this intriguing molecule.

We would like to record our sincere gratitude to all the authors who contributed to the book - without such expert and diverse input, an up-to-date volume on the haemodynamics of NO could not have been produced. It is also a pleasure to acknowledge the enthusiasm and skills provided by Aileen Parlane of Imperial College Press and Yugarani Thanabalasingam of World Scientific Publishing during the editorial and production process. In addition, our thanks go to Linda 
Theobald, Imperial College School of Medicine, and Wendy Simons, University of Wales College of Medicine, for their assistance with the detailed refinement of the manuscript. Finally, we thank both our families for their considerable patience and support during the preparation of the book.

Robert T Mathie Tudor M Griffith 


\section{List of Contributors}

\section{SL Archer}

Division of Cardiology,

University of Alberta,

Edmonton,

Alberta T6G 2B7,

Canada

\section{JE Barker}

Bernard O'Brien Institute of Microsurgery,

St Vincent's Hospital,

University of Melbourne,

Parkville,

Victoria 3065,

Australia

\section{N Benjamin}

Department of Clinical Pharmacology,

St Bartholomew's and the Royal London School of Medicine and Dentistry,

Charterhouse Square,

London EC1M 6BQ,

UK

VM Darley-Usmar

Center for Free Radical Biology and Department of Pathology,

University of Alabama,

Birmingham,

Alabama 35294,

USA

\section{AM Dart}

Department of Physiology,

University of Melbourne,

Parkville,

Victoria 3052,

Australia

\section{AT Dinh-Xuan}

Department de Physiologie et de Biologie Cellulaire,

Hôpital Cochin,

75679 Paris cedex 14,

France 


\section{K Djaballah}

Department de Physiologie et de Biologie Cellulaire,

Hôpital Cochin,

75679 Paris cedex 14,

France

\section{GJ Dusting}

Howard Florey Institute of Experimental Physiology and Medicine,

University of Melbourne,

Parkville,

Victoria 3052,

Australia

TJ Evans

Department of Infectious Diseases,

Imperial College School of Medicine,

Hammersmith Hospital,

London W12 ONN,

UK

\section{P Forte}

Department of Clinical Pharmacology,

St Bartholomew's and the Royal London School of Medicine and Dentistry, Charterhouse Square,

London EC1M 6BQ,

UK

\section{TM Griffith}

Department of Diagnostic Radiology,

University of Wales College of Medicine,

Heath Park,

Cardiff CF4 4XN,

UK

\section{PH Groves}

Department of Cardiology,

University Hospital of Wales,

Heath Park,

Cardiff CF4 4 XW,

UK

\section{H Hayakawa}

Nephrology Section,

Department of Medicine,

VA Medical Center,

University of Minnesota,

Minneapolis,

Minnesota 55417,

USA 


\section{TW Higenbottam}

Department of Medicine and Pharmacology,

Section of Respiratory Medicine,

The Medical School,

University of Sheffield,

Sheffield S10 2RX,

UK

\section{AJ Hobbs}

The Cruciform Project,

Rayne Institute,

University College London,

London WC1E 6JJ

UK

\section{Iadecola}

Department of Neurology,

University of Minnesota,

Minneapolis,

Minnesota 55455,

USA

\section{LJ Ignarro}

Department of Molecular \& Medical Pharmacology, UCLA School of Medicine,

Los Angeles,

California 90095,

USA

\section{EA Jaimes}

Nephrology Section,

Department of Medicine,

VA Medical Center,

University of Minnesota,

Minneapolis,

Minnesota 55417,

USA

\section{H Jo}

Center for Free Radical Biology and Department of Pathology, University of Alabama,

Birmingham,

Alabama 35294,

USA

\section{Jungersten}

Department of Clinical Physiology,

Sahlgrenska University Hospital,

University of Gothenburg,

S-41345 Gothenburg,

Sweden 
G Kaley

Department of Physiology,

New York Medical College,

Valhalla,

New York 10595,

USA
A Koller
Department of Physiology,
New York Medical College,
Valhalla,
New York 10595,
USA
P Kubes
Department of Medical Physiology,
Health Science Centre,
University of Calgary,
Calgary,
Alberta T2N 4N1,
Canada
D Lang

Department of Pharmacology, Therapeutics \& Toxicology, University of Wales College of Medicine,

Heath Park,

Cardiff CF4 $4 \mathrm{XN}$,

UK

\section{MJ Lewis}

Department of Pharmacology, Therapeutics \& Toxicology, University of Wales College of Medicine,

Heath Park,

Cardiff CF4 $4 \mathrm{XN}$,

UK

MC Maland

Center for Free Radical Biology and Department of Pathology, University of Alabama,

Birmingham,

Alabama 35294,

USA

\section{RT Mathie}

Division of Surgery, Anaesthetics and Intensive Care, Imperial College School of Medicine,

Hammersmith Hospital,

London W12 ONN,

UK 


\section{J McAndrew}

Center for Free Radical Biology and Department of Pathology,

University of Alabama,

Birmingham,

Alabama 35294,

USA

\section{D-M McCafferty}

Department of Medical Physiology,

Health Science Centre,

University of Calgary,

Calgary,

Alberta T2N 4N1,

Canada

ED Michelakis

Division of Cardiology,

University of Alberta,

Edmonton,

Alberta T6G 2B7,

Canada

\section{A Papapetropoulos}

Department of Pharmacology,

Boyer Center for Molecular Medicine,

Yale University School of Medicine,

New Haven,

Connecticut 06536,

USA

\section{RP Patel}

Center for Free Radical Biology and Department of Pathology, University of Alabama,

Birmingham,

Alabama 35294,

USA

\section{U Pohl}

Institute of Physiology and Pathophysiology,

Johannes Gutenberg - University of Mainz,

D-55099 Mainz,

Germany

\section{BD Prendergast}

Department of Cardiology,

University of Wales College of Medicine,

Heath Park,

Cardiff CF4 4 XN,

UK 


\title{
N Purcell
}

Center for Free Radical Biology and Department of Pathology,

University of Alabama,

Birmingham,

Alabama 35294,

USA

\section{Raij}

Nephrology Section,

Department of Medicine,

VA Medical Center,

University of Minnesota,

Minneapolis,

Minnesota 55417,

USA

\section{Rembold}

Departments of Internal Medicine and Physiology,

University of Virginia Health Sciences Center,

Charlottesville,

Virginia 22908,

USA

WC Sessa

Department of Pharmacology,

Boyer Center for Molecular Medicine,

Yale University School of Medicine,

New Haven,

Connecticut 06536,

USA

\author{
AM Shah \\ Department of Cardiology, \\ Guy's, King's \& St. Thomas' School of Medicine, \\ Denmark Hill Campus, \\ London SE5 9PJ, \\ UK \\ T Siddons \\ Department of Medicine and Pharmacology, \\ Section of Respiratory Medicine, \\ The Medical School, \\ University of Sheffield, \\ Sheffield S10 2RX, \\ UK \\ E Souil \\ Department de Physiologie et de Biologie Cellulaire, \\ Hôpital Cochin, \\ 75679 Paris cedex 14, \\ France
}




\section{GJ Southan}

Inotek Inc.,

Cincinnati,

Ohio 45219,

USA

\section{AG Stewart}

Department of Pharmacology,

University of Melbourne,

Parkville,

Victoria 3052,

Australia

\section{Szabó}

Division of Critical Care,

Children's Hospital Medical Center,

Cincinnati,

Ohio 45229,

USA

\section{Thiemermann}

The William Harvey Research Institute,

St. Bartholomew's \& The Royal London School of Medicine \& Dentistry, Charterhouse Square, London EC1M 6BQ,

UK

\section{A Wennmalm}

Department of Clinical Physiology,

Sahlgrenska University Hospital,

University of Gothenburg,

S-41345 Gothenburg,

Sweden

\section{CR White}

Molecular and Cellular Division and Department of Medicine, University of Alabama,

Birmingham,

Alabama 35294,

USA

\section{Zachariou}

Department of Pharmacology,

Boyer Center for Molecular Medicine, Yale University School of Medicine,

New Haven,

Connecticut 06536,

USA 


\section{This page is intentionally left blank}




\section{Contents}

Foreword vii

Preface $\quad$ ix

List of Contributors $\quad x i$

Part 1

Physiology and Biochemistry of Nitric Oxide 1

Chapter 1

Biochemical Effects of Nitric Oxide on Vascular Smooth Muscle 3 Derek Lang and Malcolm J Lewis

Chapter 2

Shear Stress and Nitric Oxide Release: Physiological Integration of Cellular Mechanisms, Physical Forces and Flow Regulation

Tudor M Griffith

\section{Chapter 3}

Chemistry and Molecular Biology of Nitric Oxide Synthesis Adrian J Hobbs and Louis J Ignarro

\section{Chapter 4}

The Action of Nitrovasodilator Drugs

Christopher M Rembold

\section{Chapter 5}

Nitric Oxide Synthase Biology: Insights Gained from 'Knockout'

Mice

Andreas Papapetropoulos, Venetia Zachariou and

William C Sessa

\section{Chapter 6}

The Normal Metabolic Fate of Nitric Oxide

Ake Wennmalm and Lennart Jungersten

\section{Chapter 7}

Inhibitors of Nitric Oxide Biosynthesis

Garry J Southan, Csaba Szabó and Christoph Thiemermann 
Chapter 8

Measurement of Nitric Oxide and Nitric Oxide Synthase Activity

Evangelos D. Michelakis, A Tuan Dinh-Xuan, Khier Djaballah, Evelyne Souil and Stephen $L$ Archer

Chapter 9

Hyperaemia and Autoregulation

U Pohl

\section{Part 2}

Peripheral Vascular Effects of Nitric Oxide

Chapter 10

The Role of Nitric Oxide in Cerebrovascular Regulation and Stroke

Costantino Iadecola

Chapter 11

The Physiological and Pathophysiological Effects of Nitric Oxide in the Coronary Circulation

Peter Groves

Chapter 12

The Effect of Nitric Oxide on Myocardial Function and

Dysfunction

Bernard D Prendergast and Ajay $M$ Shah

Chapter 13

Regulation of Skeletal Muscle Microcirculation by Nitric Oxide

Akos Koller and Gabor Kaley

Chapter 14

The Hepatic Haemodynamic Effects of Nitric Oxide

Robert T Mathie

\section{Chapter 15}

The Physiological and Pathophysiological Effects of Nitric Oxide on the Intestinal Circulation

Donna-Marie McCafferty and Paul Kubes

Chapter 16

The Pathophysiological and Physiological Effects of Nitric Oxide on the Renal Circulation

Edgar A Jaimes, Hiroshi Hayakawa and Leopoldo Raij 


\section{Part 3}

\section{Clinical Implications of Nitric Oxide}

Chapter 17

Organ Ischaemia-reperfusion Injury: The Role and Therapeutic

Potential of Nitric Oxide

Alastair G Stewart and Jane E Barker

Chapter 18

Oxidative Tissue Injury, Nitric Oxide and Atherosclerosis

Rakesh P. Patel, Joanne McAndrew, Nicole Purcell,

Matthew C. Maland, Hanjoong Jo, C. Roger White and

Victor M. Darley-Usmar

Chapter 19

Endothelial Dysfunction Associated with Cardiovascular Disease and Transplantation

Gregory J Dusting and Anthony M Dart

\section{Chapter 20}

The Effects of Nitric Oxide in the Pulmonary Circulation

Tom Siddons and Tim Higenbottam

\section{Chapter 21}

The Role and Therapeutic Implications of Nitric Oxide in Systemic Hypertension

Pablo Forte and Nigel Benjamin

Chapter 22

The Role of Nitric Oxide in Septic Shock and Other Inflammatory Conditions

$T J$ Evans

Index 